\title{
Angiotensin II Type 1a Receptor Signals are Involved in the Progression of Heart Failure in $M L P$-Deficient Mice
}

\author{
Rie Yamamoto, MD*; Hiroshi Akazawa, MD*,**; Kaoru Ito, MD*; Haruhiro Toko, MD*; \\ Masanori Sano, MD*; Noritaka Yasuda, MD*; Yingjie Qin, MD*; Yoko Kudo, MD*; \\ Takeshi Sugaya, MSc ${ }^{\dagger}$; Kenneth R. Chien, MD ${ }^{\dagger}$; Issei Komuro, MD*
}

\begin{abstract}
Background Angiotensin II (AT) is implicated in the development of cardiac remodeling, which leads to heart failure, and pharmacological inhibition of the AT type 1 (AT1) receptor has improved mortality and morbidity in patients of heart failure. The aim of this study was to elucidate the role of the AT1 receptor in disease progression in muscle LIM protein $(M L P)$-deficient mice, which are susceptible to heart failure because of defective function of mechanosensors in cardiomyocytes.

Method and Results Hearts from MLP knockout (MLPKO) mice and MLP-ATla receptor double knockout (DKO) mice were analyzed. MLPKO hearts showed marked chamber dilatation with cardiac fibrosis and reactivation of the fetal gene program. All of these changes were significantly milder in the DKO hearts. Impaired left ventricular (LV) contractility and filling were alleviated in DKO hearts. However, the impaired relaxation and downregulated expression of sarcoplasmic reticulum calcium-ATPase 2 were unchanged in DKO hearts.

Conclusions The AT1a receptor is involved in progression of LV remodeling and deterioration of cardiac function in the hearts of MLPKO mice. These results suggest that blockade of the receptor is effective in preventing progression of heart failure in dilated cardiomyopathy. (Circ J 2007; 71: 1958-1964)
\end{abstract}

Key Words: Angiotensin II; Cardiomyopathy; Heart failure; Remodeling; Sarcoplasmic reticulum

A growing body of evidence suggests that blockade of the renin-angiotensin system (RAS) leads to a decrease in the morbidity and mortality of patients with congestive heart failure! In addition to the systemic effects, including elevation of blood pressure (BP), sodium and water retention, and activation of the sympathetic nervous system, the activated RAS has unfavorable direct effects on the heart? 2 Most of the known functions of angiotensin II (Ang II) in the cardiovascular system are mainly mediated through the Ang II type 1 (AT1) receptor? In mice or rats, the AT1 receptor has 2 subtypes (AT1a and AT1b), but the AT1a receptor is predominantly expressed and functionally important in cardiomyocytes., ${ }^{4}$ According to the results of in vitro experiments, activation of the AT1 receptor stimulates diverse intracellular signaling cascades and produces reactive oxygen species, which evoke hypertrophic responses in cardiomyocytes and enhance cellular proliferation and production of extracellular matrix proteins, such as collagen, in cardiac fibroblasts2,6 These cellular alterations that occur within the heart would promote left ventricular (LV) remodeling and contribute to the progres-

(Received March 29, 2007; revised manuscript received July 20, 2007; accepted July 31, 2007)

*Department of Cardiovascular Science and Medicine, **Division of Cardiovascular Pathophysiology, Chiba University Graduate School of Medicine, Chiba, Discovery Laboratory, Tanabe Seiyaku Co, Ltd, Osaka, Japan and ${ }^{\dagger}$ Cardiovascular Research Center, Massachusetts General Hospital, Boston, MA, USA

Mailing address: Issei Komuro, MD, Department of Cardiovascular Science and Medicine, Chiba University Graduate School of Medicine, 1-8-1 Inohana, Chuo-ku, Chiba 260-8670, Japan. E-mail: komuro-tky @ umin.ac.jp sion of heart failure. However, the effects of the AT1 receptor have been experimentally verified only in animal models of heart failure, such as a myocardial infarction model produced by coronary artery ligation, ${ }^{7-9}$ a pacing-induced heart failure model ${ }^{10}$ Dahl salt-sensitive rats ${ }^{11}$ a pressure-overloaded model $1^{12,13}$ a shunt-induced volume-overloaded model ${ }^{14}$ experimental myocarditis, 5 and doxorubicininduced cardiomyopathy 16 A number of reports have suggested that inhibition of the AT1 receptor prevents LV remodeling after myocardial infarction, ${ }^{2,7-9}$ but it remains unknown whether it is also beneficial for dilated cardiomyopathy (DCM).

Mice deficient for the gene for muscle LIM protein $(M L P)$ have been characterized as a good model of human DCM ${ }^{17}$ MLP, a member of the LIM-only proteins ${ }^{18}$ is involved in organization of cytoarchitecture ${ }^{17}$ and is proposed to function as a mechanosensor ${ }^{19}$ Approximately $35 \%$ of $M L P$-deficient mice (offspring of homozygous breeders) exhibit an early phenotype with marked hypertrophy and death within 10-11 days, and remainder survive into adulthood and exhibit a number of phenotypic features of human DCM (adult phenotype) ${ }^{17}$ In the present study, we used $M L P$-deficient mice as a model of DCM and examined the effects of $\mathrm{AT}_{1}$ receptor blockade on disease progression using $A T_{l a}$-deficient mice.

\section{Methods}

\section{Animals}

G1 pups generated from an $M L P^{+/-}$heterozygote $\times A \mathrm{Ta}^{-1-}$ homozygote cross were mated to created the $M L P^{+1-l}$ $A T_{1 a^{+/}}$double heterozygotes (G2). G4 offspring were gen- 
A
WT
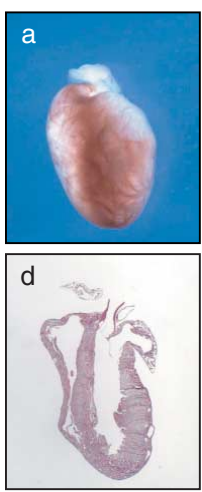

C

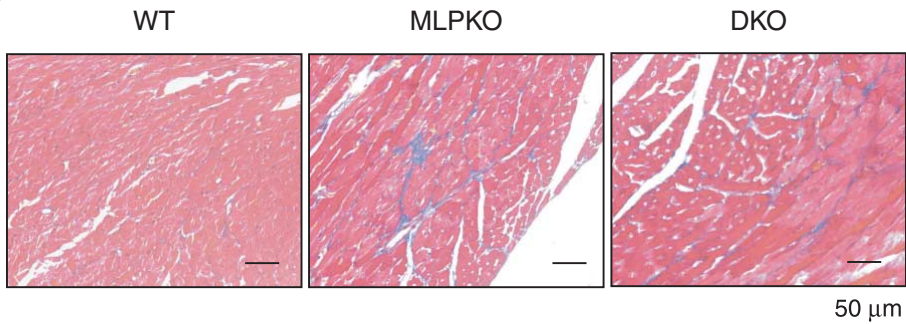

D

Area of fibrosis (\%)

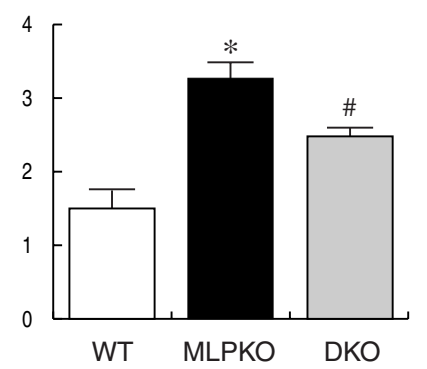

B

$\mathrm{H} / \mathrm{B}$ ratio

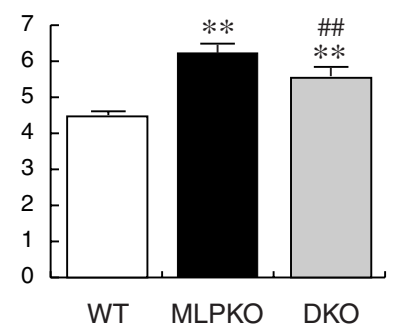

Fig 1. Rescue of the morphological and histological changes in double knockout (DKO) hearts. (A) $(\mathrm{a}-\mathrm{c})$ Excised hearts from 24-weekold wild-type (WT), muscle LIM proteinknockout (MLPKO) and DKO mice. (d-f) Histological analysis of 4-chamber sections (hematoxylin-eosin). Marked chamber dilatation in MLPKO hearts (e) was rescued in the DKO hearts (f). (B) Heart-to-body weight ratio $(\mathrm{H} / \mathrm{B}$ ratio $(\mathrm{mg} / \mathrm{g}))$. $\mathrm{n}=20$. (C) Histological analysis of light micrographs of cardiac fibrosis (stained blue) in left ventricle wall sections from WT, MLPKO and DKO mice at 24 weeks of age (Masson's trichrome; $\times 100$ ). (D) Quantification of fibrotic area in the hearts. Data are mean \pm SEM of 6 independent experiments. $* * \mathrm{p}<0.01, * \mathrm{p}<0.05$ : WT vs MLPKO or DKO; ${ }^{\#} \mathrm{p}<0.01,{ }^{*} \mathrm{p}<0.05$ : MLPKO vs DKO. erated from $M L P^{+/-} / A T 1 a^{+/-}$matings (G3). The genotypes of the gene-targeted crosses were determined by PCR on genomic DNA isolated from tail biopsies as described previously 17,20 We analyzed 24-week-old G4 offspring of the same crosses according to 3 groups: wild-type (WT) mice $\left(\mathrm{MLP}^{+/+} / \mathrm{AT}_{1 a^{+/+}}\right)$, MLP-knockout (MLPKO) mice $\left(M L \mathrm{P}^{-/-}\right.$ $\left.A T_{1 a^{+/+}}\right)$and double knockout (DKO) mice $\left(M L P^{-l-} / A T_{1 a^{-l-}}\right)$. All protocols were approved by the Institutional Animal Care and Use Commmittee of Chiba University.

\section{Histological Analysis}

Hearts were fixed in $10 \%$ neutralized formalin and embedded in paraffin. Serial sections at $4 \mu \mathrm{m}$ were routinely stained with hematoxylin-eosin for morphological analysis, and with Masson's trichrome for detection of fibrosis 21 The images were acquired by stereomicroscope (MZ12, Leica, Tokyo, Japan) and captured by DC100 program (Leica), or by light microscope (Axioskop 2 plus, Carl Zeiss, Oberkochen, Germany) and captured by Axio Cam CCD camera and Axio Vision 3.0 imaging system (Carl Zeiss). The fibrotic areas by Masson's trichrome staining were calculated with image analysis software Adobe Photoshop (Adobe Systems, CA, USA).

\section{Physiological Studies}

BPs and pulse rates were measured in conscious mice noninvasively by a standard tail-cuff method (Softron). After anesthetizing the mice by intraperitoneal injection of a mixture of ketamin $(50 \mathrm{mg} / \mathrm{kg})$ and xylazine $(2.5 \mathrm{mg} / \mathrm{kg})$, transthoracic echocardiograms were recorded with an echocardiographic system (SONOS 4500, Philips Medical Systems, Andover, MA, USA) using a 12-MHz imaging transducer as described previously!6,21 For hemodynamic measurements, a pressure transducer (Samba Sensors, Göteborg, Sweden) was inserted into the LV via the right carotid artery. Heart rate, LV systolic pressure, LV enddiastolic pressure (LVEDP), positive and negative first derivatives for maximal rates of $\mathrm{LV}$ pressure development ( $\max \mathrm{dP} / \mathrm{dt}$ and $\min \mathrm{dP} / \mathrm{dt}$ ), were acquired digitally by a data acquisition system (SAMBA3000, Samba Sensors). The time constant of LV isovolumetric pressure decay (tau) was calculated according to a variable asymptote method.2

\section{Northern Blot Analysis}

Total RNA (10 $\mathrm{g}$ ) was extracted from the LV with TRIzol (Invitrogen) and was hybridized with the [a-32P]dCTP-labeled cDNA probes for brain natriuretic peptide $(B N P)$, skeletal a-actin, and sarcoplasmic reticulum cal- 
Table 1 BPs and Pulse Rates

\begin{tabular}{lccc}
\hline \hline & $W T$ & MLPKO & DKO \\
\hline$N$ & 5 & 5 & 3 \\
Pulse rate (beats/min) & $643.9 \pm 15.5$ & $640.2 \pm 7.1$ & $636.5 \pm 20.9$ \\
Systolic BP $(\mathrm{mmHg})$ & $96.3 \pm 3.3$ & $80.4 \pm 1.6^{* *}$ & $71.9 \pm 0.9^{* * \#}$ \\
Diastolic BP $(\mathrm{mmHg})$ & $60.3 \pm 3.9$ & $55.5 \pm 1.4$ & $39.1 \pm 4.6^{* \#}$ \\
Mean BP $(\mathrm{mmHg})$ & $72.3 \pm 3.3$ & $63.8 \pm 0.7 *$ & $50.1 \pm 3.4^{* * \# \#}$ \\
\hline
\end{tabular}

$B P$, blood pressure; WT, wild type; MLPKO, muscle LIM protein knockout; DKO, double knockout.

Data are mean $\pm S E M$.

${ }^{* *} p<0.01,{ }^{*} p<0.05$ : WT vs MLPKO or DKO; ${ }^{\#} p<0.01,{ }^{\#} p<0.05:$ MLPKO vs DKO.

A

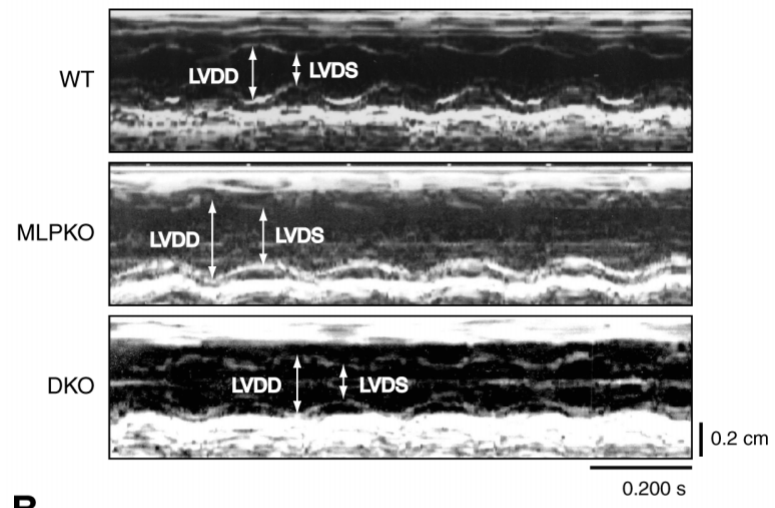

B

\begin{tabular}{lccc}
\hline & WT & MLPKO & DKO \\
\hline Number & 16 & 16 & 16 \\
Body weight (g) & $29.0 \pm 0.8$ & $30.1 \pm 1.2$ & $27.2 \pm 0.9$ \\
Heart rate (beats/min) & $302.6 \pm 4.6$ & $294.2 \pm 6.8$ & $296.9 \pm 6.4$ \\
LVDD $(\mathrm{mm})$ & $3.66 \pm 0.08$ & $4.54 \pm 0.10 * *$ & $3.96 \pm 0.09 *$, \#\# \\
LVSD $(\mathrm{mm})$ & $2.13 \pm 0.07$ & $3.56 \pm 0.11 * *$ & $2.77 \pm 0.10^{* *}$, \#\# \\
FS $(\%)$ & $41.7 \pm 1.4$ & $21.8 \pm 1.3 * *$ & $30.2 \pm 1.1 * *$ *\# \\
LVPWT $(\mathrm{mm})$ & $0.52 \pm 0.03$ & $0.52 \pm 0.04$ & $0.54 \pm 0.03$ \\
LVDD $(\mathrm{mm}) /$ LVPWT $(\mathrm{mm})$ & $7.51 \pm 0.49$ & $9.48 \pm 0.67 *$ & $7.63 \pm 0.39 \#$
\end{tabular}

Fig 2. Rescue of cardiac chamber dilatation and dysfunction in double knockout (DKO) mice. Representative transthoracic M-mode echocardiograms obtained at the level of papillary muscles. Echocardiographic parameters. Data are mean \pm SEM. LVDD, left ventricular end-diastolic dimension; LVSD, left ventricular end-systolic dimension; FS, fractional shortening; LVPWT, left ventricular posterior wall thickness; WT, wild-type; MLPKO, muscle LIM protein-knockout; DKO, double knockout. **p $<0.01,{ }^{*} \mathrm{p}<0.05$ : WT vs MLPKO or DKO; $\# \mathrm{p}<0.01, \# \mathrm{p}<0.05$ : MLPKO vs DKO.

Table 2 Hemodynamic Characteristics

\begin{tabular}{lccc}
\hline \hline & $W T$ & MLPKO & DKO \\
\hline Number & 5 & 5 & 5 \\
Heart rate (beats/min) & $368.8 \pm 25.9$ & $358.1 \pm 32.2$ & $349.6 \pm 20.3$ \\
Mean AoP $(\mathrm{mmHg})$ & $91.4 \pm 3.4$ & $79.9 \pm 6.0$ & $59.6 \pm 4.35^{*, \#}$ \\
LVEDP $(\mathrm{mmHg})$ & $5.4 \pm 1.5$ & $32.9 \pm 7.3^{*}$ & $7.1 \pm 2.2^{\#}$ \\
Max dP/dt & $4,669 \pm 258$ & $2,070 \pm 295^{* *}$ & $3,415 \pm 307^{* \#}$ \\
- min dP/dt & $4,304 \pm 233$ & $2,306 \pm 208^{* *}$ & $2,561 \pm 111^{* *}$ \\
Tau (ms) & $15.56 \pm 2.76$ & $44.76 \pm 6.12^{* *}$ & $26.78 \pm 5.33$ \\
\hline
\end{tabular}

AoP; aortic pressure; LVEDP, left ventricular end-diastolic pressure; max $d P / d t$, maximal rate of left ventricular pressure rise; min $d P / d t$, minimal rate of left ventricular pressure fall; tau, time constant of left ventricular isovolumetric pressure decay. Other abbreviations see in Table 1.

Data are mean $\pm S E M$.

${ }^{* *} p<0.01,{ }^{*} p<0.05:$ WT vs MLPKO or DKO; ${ }^{*} p<0.01,{ }^{*} p<0.05: M L P K O$ vs DKO. cium $\left(\mathrm{Ca}^{2+}\right)$-ATPase (SERCA) 2 as previously described ${ }^{21}$ Hybridized bands were quantified with NIH IMAGE software (NIH, Research Service Branch).

\section{Western Blot Analysis}

Total proteins were fractionated by SDS PAGE and transferred to Hybond membranes (GE Healthcare Life Sciences, Buckinghamshire, UK). The blotted membranes were incubated with the following antibodies, as described previously: ${ }^{21}$ polyclonal antibody against ryanodine receptor (RyR2) (Oncogene Research Products, rabbit polyclonal antibody against phosphorylated phospholamban (Ser-16) (Upstate Biotech, Charlottesville, VA, USA), mouse monoclonal antibody against phospholamban (PLN) (Oncogene Research Products, San Diego, CA, USA), mouse monoclonal antibody against SERCA2 (Oncogene Research Products), and rabbit polyclonal antibody against Actin (Sigma-Aldrich).

\section{Statistical Analysis}

All data are expressed as mean \pm SEM. Differences in measured values were evaluated with an analysis of variance using Fisher's t-test and unpaired Student's t-test. Values of $\mathrm{p}<0.05$ were considered to be statistically significant.

\section{Results}

Cardiac Morphological Changes and Fibrosis

Macroscopic inspection and histological sections revealed global chamber dilatation in MLPKO hearts at 24 weeks of age (Fig 1A), as previously described ${ }^{17}$ In addition, MLPKO mice displayed a marked increase in the heart-to-body weight ratio (H/B ratio, $6.23 \pm 0.21 \mathrm{mg} / \mathrm{g}$ ), compared with gender-matched WT mice $(4.47 \pm 0.14 \mathrm{mg} / \mathrm{g})$ (Fig 1B). These apparent cardiomyopathic features were alleviated in the DKO mice. Chamber dilatation was not prominent in DKO mice (Fig 1A), and the H/B ratios were significantly smaller $(5.54 \pm 0.21 \mathrm{mg} / \mathrm{g})$ than those of the MLPKO mice (Fig 1B).

Masson's trichrome staining revealed more marked cardiac fibrosis in MLPKO hearts $(3.27 \pm 0.19 \%$ of total myocardial area) than in WT hearts ( $1.5 \pm 0.23 \%$ of total myocardial area) (Fig 1C). Cardiac fibrosis was also significantly attenuated in the DKO hearts $(2.48 \pm 0.12 \%$ of total myocardial area) (Figs 1C,D). These results suggest that genetic ablation of the AT1a receptor prevents the morphological and histological changes observed in the hearts of MLPKO mice.

\section{Cardiac Function}

The BP and pulse rates are shown in Table 1. There were no differences in pulse rate in any of the groups, but the BP was significantly lower in MLPKO mice than in WT mice (mean BP, $\mathrm{p}<0.05$ ), presumably because of the low cardiac output in MLPKO mice. Genetic disruption of the AT1a receptor further lowered BP in MLPKO mice (mean BP, $\mathrm{p}<0.01$, MLPKO vs DKO) 20

To examine whether the deterioration in cardiac performance in MLPKO mice was rescued in DKO mice, we first performed echocardiography with 24-week-old mice (Fig 2). MLPKO mice showed a 1.2-fold increase in LV end-diastolic dimensions (LVDD) and a 1.9-fold decrease in the percent of fractional shortening (\%FS) of the LV, when compared with WT mice (LVDD, $\mathrm{p}<0.01 ; \% \mathrm{FS}, \mathrm{p}<0.01$ ) (Fig 2B). However, these parameters showed significant improvement in DKO mice (LVDD, $\mathrm{p}<0.01 ; \% \mathrm{FS}, \mathrm{p}<0.01$, 
A

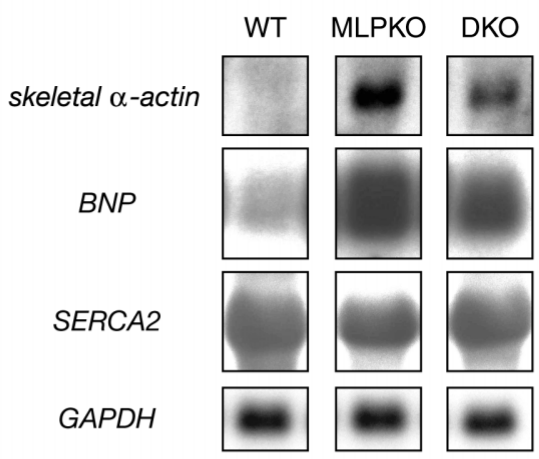

B

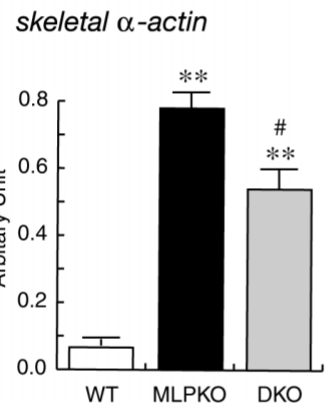

$B N P$
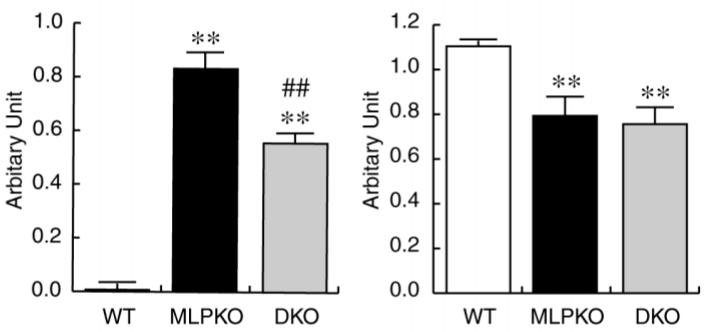

SERCA2
C

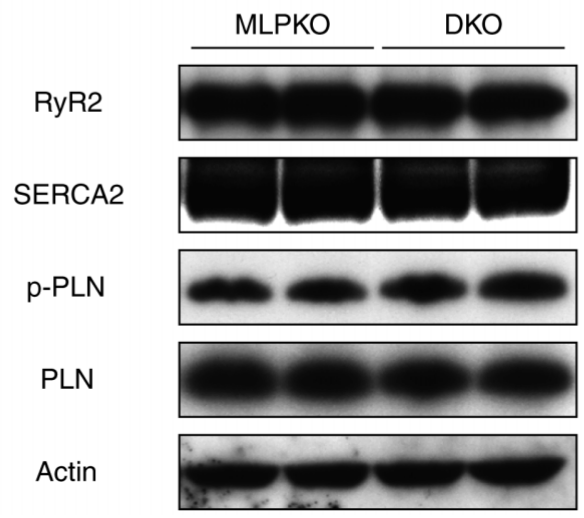

Fig 3. Cardiac gene expression in the left ventricle. (A) Representative autoradiograms of northern blot analysis for expressions of skeletala-actin, brain natriuretic peptide $(B N P)$ and sarcoplasmic reticulum $\mathrm{Ca}^{2+}$-ATPase 2 (SERCA2). (B) The intensity of each band is quantified and corrected for the amount of glyceraldehyde phosphate dehydrogenase $(G A P D H)$ mRNA. Data are mean \pm SEM of 6 independent experiments. WT, wild-type; MLPKO, muscle LIM protein-knockout; DKO, double knockout; RyR2, ryanodine receptor; $p$-PLN, phosphorylated phospholamban; PLN, phospholamban. **p<0.01: WT vs MLPKO or DKO; \#\# $<0.01$, ${ }^{*} \mathrm{p}<0.05$ : MLPKO vs DKO. (C) Immunoblot analysis showing unchanged expression levels of the $\mathrm{Ca}^{2+}$ handling proteins in the SR.
MLPKO vs DKO) (Fig 2B), indicating that genetic ablation of the AT1a receptor prevented progression of ventricular dilatation and systolic dysfunction. Although the LV posterior wall thickness (LVPWT) showed no significant difference, the ratio of LVDD to LVPWT was normalized in DKO (Fig 2B), which suggested that the wall stress in DKO hearts was relieved ${ }^{23}$ by the absence of the AT1a receptor.

To further evaluate the cardiac performance of the WT, MLPKO and DKO mice, several independent hemodynamic parameters were measured by cardiac catheterization in anesthetized mice (Table 2). Max dP/dt was significantly decreased in MLPKO mice ( $\mathrm{p}<0.01$, vs WT mice), indicating depression of LV contractility. Genetic ablation of the $\mathrm{AT}_{1}$ receptor led to a significant increase in $\max \mathrm{dP} / \mathrm{dt}$ in the MLPKO mice ( $p<0.05$, MLPKO vs DKO), confirming improved LV contractility in the DKO mice. LVEDP was significantly elevated in MLPKO mice $(32.9 \pm 7.3 \mathrm{mmHg}$, vs $5.4 \pm 1.5 \mathrm{mmHg}$ in WT mice, $\mathrm{p}<0.01)$, indicating increased cardiac stiffness. Notably, the LVEDP in DKO mice was almost normal $(7.1 \pm 2.2 \mathrm{mmHg})$. Likewise, $\mathrm{min} \mathrm{dP} / \mathrm{dt}$ was markedly reduced and tau was significantly prolonged in the MLPKO mice (min dP/dt: $\mathrm{p}<0.01$, tau: $\mathrm{p}<0.01$, vs WT).
However, DKO mice showed only a slight improvement in these parameters for $\mathrm{LV}$ relaxation $(\mathrm{min} \mathrm{dP} / \mathrm{dt}$ : $\mathrm{p}=0.31$, tau: $\mathrm{p}=0.06$, vs MLPKO).

\section{Gene Expressions in MLPKO and DKO Hearts}

To characterize the molecular basis of the effects of AT1a receptor ablation, we examined expression levels of molecular markers for cardiac hypertrophy and failure. Reactivation of the fetal cardiac gene program is a typical cellular response observed during cardiac hypertrophy? The MLPKO hearts showed a remarkable increase in expressions of skeletala-actin and $B N P$, when compared with WT hearts (Fig 3). In DKO hearts, the upregulation of skeletala-actin and $B N P$ expressions was milder than that in MLPKO hearts (skeletal a -actin, $\mathrm{p}<0.05 ; B N P, \mathrm{p}<0.05$, MLPKO vs DKO) (Figs 3A,B). These results suggest that genetic ablation of the AT1a receptor also prevented alterations in gene expression.

Downregulation of SERCA2 is considered to be a feature characteristic of human patients and animal models of heart failure ${ }^{25}$ In the present study, the MLPKO hearts consistently showed a 1.4-fold reduction in SERCA2 expression, 
when compared with WT hearts (Figs 3A,B). In contrast to the blunted upregulation of skeletal a-actin and $B N P$, the expression level of SERCA2 in the DKO hearts was comparable to that in MLPKO hearts (Figs 3A,B). We further confirmed that the levels of SERCA2 in MLPKO and DKO hearts were comparable (Fig 3C). These results suggest that blockade of the AT1a receptor had a marginal effect on the expression of SERCA2 in MLPKO hearts. In addition, MLPKO and DKO hearts showed no significant differences in the levels of $\mathrm{Ca}^{2+}$ regulatory proteins in the SR, such as RyR2 and PLN (both phosphorylated and total PLN) (Fig 3C).

\section{Discussion}

Many clinical studies have indicated that pharmacological inhibition of the RAS can reduce overall the mortality and morbidity in patients with heart failure? However, the clinical syndrome of heart failure is the final state of a wide spectrum of diseases affecting the heart ${ }^{1,26}$ and the effects of RAS inhibition may differ according to the causation, genetic and environmental backgrounds, and disease stage. To gain insights into the in vivo effects of RAS inhibition on the development and progression of heart failure, several animal models have been utilized; ${ }^{8-16,27}$ however, most do not perfectly represent human heart failure ${ }^{28}$ and the effects of RAS inhibition are unknown in a mouse model of DCM caused by mutations affecting the cytoskeleton and sarcomere. In this regard, we are the first to analyze the preventive effects of AT1a receptor blockade on progression of heart failure in $M L P$-deficient cardiomyopathic mice.

Genetic explorations have revealed that aberrant force generation or transmission caused by cytoskeletal abnormalities is an important pathogenic factor in DCM $2^{29}$ MLP was originally identified as an essential regulator of cardiac muscle development, serving as a scaffold protein promoting the assembly of the actin-based cytoskeleton ${ }^{18} \mathrm{~A}$ recent report demonstrated that MLP stabilizes a protein complex at the $\mathrm{Z}$ disc, which anchors the actin filaments and functions as a key component of the intrinsic mechanosensor in cardiomyocytes $!^{19}$ Accordingly, $M L P$-deficient mice exhibit chamber dilatation and cardiac dysfunction, ${ }^{17}$ possibly because stretch-induced survival responses are not stimulated in response to increased wall stress ${ }^{19}$ Defects in stabilization of the $\mathrm{Z}$ disc complex involving the MLP protein might be important in the pathogenesis of human DCM as well, because a human MLP mutation is associated with DCM ${ }^{19}$ and MLP protein levels are decreased in the hearts of patients with idiopathic and ischemic cardiomyopathies 30 Therefore, $M L P$-deficient mice are considered to be a good model for human DCM.

The present study demonstrated that genetic ablation of the AT1a receptor could rescue the cardiomyopathic phenotype of MLPKO. AT1a receptor blockade suppressed morphological and histological changes characterized by chamber dilatation and cardiac fibrosis (Fig 1). Similarly, hypertrophic gene reprogramming was attenuated in the absence of the ATla receptor, because reactivation of $B N P$ and skeletala-actin expressions was less prominent (Figs 3A,B). These findings suggest that $\mathrm{AT}_{1}$ a receptor blockade prevents the progression of maladaptive structural LV remodeling in MLPKO hearts as in other heart failure models? In addition, precise evaluation of hemodynamic parameters by echocardiography and cardiac catheterization revealed that AT1a receptor blockade led to an improvement of cardiac perfor- mance in MLPKO mice (Fig 2, Table 2). Mechanistically, an improvement of LV contractility, as evidenced by increased $\% \mathrm{FS}$ and $\max \mathrm{dP} / \mathrm{dt}$, might result from restoration of the geometric changes in the DKO hearts. Alternatively, the negative inotropic effects of Ang II might be alleviated, because it has been reported that Ang II reduces LV contractility in failing hearts through the AT1 receptor ${ }^{31-33}$ In addition, a recent study reported that pharmacological inhibition of the AT1 receptor restores cardiac RyR2 function in the isoproterenol-induced failing heart ${ }^{34}$ However, a reduction in BP in the absence of the AT1a receptor may have beneficial effects in DKO hearts. In particular, an improvement of LV contractility may be caused in part by diminished afterload. Further experiments are required to dissect the effects of AT1a receptor blockade on cardiac contractility in vivo, at least by using a control group, to treat MLPKO mice with a BP-lowering agent or by confining gene deletion to the myocardium.

As reported previously ${ }^{23,35-37}$ MLPKO hearts show an increase in passive stiffness. Normalization of the LVEDP in the DKO hearts indicated that the impaired filling in the MLPKO hearts was rectified in the absence of the AT1a receptor (Table 2). It is well established that accumulation of interstitial collagen results in increased wall stiffness, which in turn impairs LV filling and increases the LVEDP. Suppression of cardiac fibrosis might contribute to decreased stiffness of the DKO hearts. In comparison with the LVEDP, min $\mathrm{dP} / \mathrm{dt}$ and tau showed subtle improvement in the DKO hearts (Table 2). Although it is difficult to assign specific biochemical mechanisms to the impaired lusitropy, these results suggest that $\mathrm{AT}_{1}$ a receptor blockade has a marginal effect on relaxation during isovolumic early diastole 38,39 Slowed relaxation may be caused by declined pumping activities of the SR, which are often coupled to reduced expression of SERCA2 (reviewed by Kass et al ${ }^{39}$ ). Consistently, the DKO hearts did not show a significant difference with MLPKO hearts in SERCA2 expression (Fig 3). In addition, no significant differences were observed in the phosphorylation levels of PLN, an inhibitory regulator for SERCA2, in either MLPKO or DKO hearts (Fig 3C). In line with this speculation, it has been reported that genetic ablation of $P L N$ normalized $\mathrm{min} \mathrm{dP} / \mathrm{dt}$, as well as LVEDP, in MLPKO hearts 23 Insomuch as AT1 receptor blockade has been reported to restore slowed relaxation during isovolumic diastole in other models of heart failure, $8,11,12,34$ insufficient restoration of SR function by AT1a receptor blockade may be a phenomenon occurring specifically in failing hearts caused by abnormalities of the cytoskeleton or sarcomere. On the basis of the functional role of MLP as a key component of the mechanosensor ${ }^{19}$ restoration of SERCA2 expression might be dependent on the stretch sensor machinery at the $\mathrm{Z}$ disc that perceives and mediates the alterations of wall stress. In addition, intracellular $\mathrm{Ca}^{2+}$ handling is intricately influenced by multiple signaling pathways in cardiomyocytes ${ }^{40}$ and further experiments are required to elucidate the precise role of $\mathrm{AT}_{1} \mathrm{a}$ signaling in the regulation of SR function.

Although mechanical stress is the primary trigger that stimulates structural and functional alterations in cardiomyocytes (reviewed by Komuro and Yazaki; ${ }^{41}$ Sadoshima and Izumo ${ }^{42}$ ), it remains unclear how mechanical stress is perceived and converted into active intracellular signaling. Besides the $\mathrm{Z}$ disc complex involving MLP, integrins and their associated signaling machinery and stretch-activated ion channels have been reported to be sensors for mechani- 
cal stress. ${ }^{4-46}$ In addition, we recently demonstrated that the $\mathrm{AT}_{1}$ receptor itself may function as a receptor for mechanical stress. ${ }^{47}$ However, it is unknown how the mechanosensors are activated by mechanical stress and how they regulate the wide variety of stretch-induced responses, especially in failing hearts. Although the expressions and activities of RAS components were not examined in MLPKO hearts, our present study results suggest that the AT1a receptor also plays a critical role in the progression of heart failure caused by a defect of the $\mathrm{Z}$ disc mechanosensor machinery.

We conclude that genetic ablation of the AT1a receptor prevents progression of $\mathrm{LV}$ remodeling and deterioration of cardiac contractility and filling in the hearts of MLPKO mice, which are a good model of DCM caused by defective function of a mechanosensor in cardiomyocytes. In addition, our present study has highlighted distinctive effects of AT1a receptor blockade on impaired lusitropy according to the pathophysiology of the underlying disease.

\section{Acknowledgments}

We thank M. Ikeda, A. Furuyama, Y. Ohtsuki, I. Sakamoto and M. Takamura for their excellent technical assistance. This work was supported in part by grants from the Japanese Ministry of Education, Culture, Sports, Science and Technology; Health and Labor Sciences Research Grants; Japan Health Sciences Foundation; Takeda Medical Research Foundation; Takeda Science Foundation; Uehara Memorial Foundation; Kato Memorial Trust for Nambyo Research; Japan Medical Association (to I. K.); from Uehara Memorial Foundation; Sakakibara Memorial Research Grant from The Japan Research Promotion Society for Cardiovascular Diseases, Mochida Memorial Foundation, Japanese Heart Foundation/Novartis Research Award on Molecular and Cellular Cardiology, Mitsubishi Pharma Research Foundation, and Japan Intractable Diseases Research Foundation (to H. A.).

\section{References}

1. Jessup M, Brozena S. Heart failure. N Engl J Med 2003; 348: 2007 2018.

2. Kim S, Iwao H. Molecular and cellular mechanisms of angiotensin II-mediated cardiovascular and renal diseases. Pharmacol Rev 2000; 52: $11-34$.

3. Timmermans PB, Wong PC, Chiu AT, Herblin WF, Benfield P, Carini DJ, et al. Angiotensin II receptors and angiotensin II receptor antagonists. Pharmacol Rev 1993; 45: 205-251.

4. Harada K, Komuro I, Zou Y, Kudoh S, Kijima K, Matsubara H, et al. Acute pressure overload could induce hypertrophic responses in the heart of angiotensin II type 1a knockout mice. Circ Res 1998; 82: $779-785$.

5. Kudoh S, Komuro I, Hiroi Y, Zou Y, Harada K, Sugaya T, et al. Mechanical stretch induces hypertrophic responses in cardiac myocytes of angiotensin II type 1a receptor knockout mice. J Biol Chem 1998; 273: 24037-24043.

6. Hunyady L, Catt KJ. Pleiotropic AT1 receptor signaling pathways mediating physiological and pathogenic actions of angiotensin II. Mol Endocrinol 2006; 20: 953-970.

7. Pfeffer JM, Pfeffer MA, Braunwald E. Influence of chronic captopril therapy on the infarcted left ventricle of the rat. Circ Res 1985; 57: $84-95$.

8. Ambrose J, Pribnow DG, Giraud GD, Perkins KD, Muldoon L, Greenberg BH. Angiotensin type 1 receptor antagonism with irbesartan inhibits ventricular hypertrophy and improves diastolic function in the remodeling post-myocardial infarction ventricle. J Cardiovasc Pharmacol 1999; 33: 433-439.

9. Harada K, Sugaya T, Murakami K, Yazaki Y, Komuro I. Angiotensin II type 1A receptor knockout mice display less left ventricular remodeling and improved survival after myocardial infarction. Circulation 1999; 100: 2093-2099.

10. Spinale FG, Mukherjee R, Iannini JP, Whitebread S, Hebbar L, Clair $\mathrm{MJ}$, et al. Modulation of the renin-angiotensin pathway through enzyme inhibition and specific receptor blockade in pacing-induced heart failure. II: Effects on myocyte contractile processes. Circulation 1997; 96: 2397-2406.

11. Yamamoto K, Masuyama T, Sakata Y, Mano T, Nishikawa N,
Kondo H, et al. Roles of renin-angiotensin and endothelin systems in development of diastolic heart failure in hypertensive hearts. Cardiovasc Res 2000; 47: 274-283.

12. Takeishi Y, Bhagwat A, Ball NA, Kirkpatrick DL, Periasamy M, Walsh RA. Effect of angiotensin-converting enzyme inhibition on protein kinase C and SR proteins in heart failure. Am J Physiol 1999; 276: $\mathrm{H} 53-\mathrm{H} 62$.

13. Zhang C, Yasuno S, Kuwahara K, Zankov DP, Kobori A, Makiyama $\mathrm{T}$, et al. Blockade of angiotensin II type 1 receptor improves the arrhythmia morbidity in mice with left ventricular hypertrophy. Circ J 2006; 70: 335-341.

14. Ruzicka M, Yuan B, Leenen FH. Effects of enalapril vs losartan on regression of volume overload-induced cardiac hypertrophy in rats. Circulation 1994; 90: 484-491.

15. Godsel LM, Leon JS, Engman DM. Angiotensin converting enzyme inhibitors and angiotensin II receptor antagonists in experimental myocarditis. Curr Pharm Des 2003; 9: 723-735.

16. Toko H, Oka T, Zou Y, Sakamoto M, Mizukami M, Sano M, et al. Angiotensin II type 1a receptor mediates doxorubicin-induced cardiomyopathy. Hypertens Res 2002; 25: 597-603.

17. Arber S, Hunter JJ, Ross J Jr, Hongo M, Sansig G, Borg J, et al. MLP-deficient mice exhibit a disruption of cardiac cytoarchitectural organization, dilated cardiomyopathy, and heart failure. Cell 1997; 88: $393-403$.

18. Arber S, Halder G, Caroni P. Muscle LIM protein, a novel essential regulator of myogenesis, promotes myogenic differentiation. Cell 1994; 79: 221-231.

19. Knoll R, Hoshijima M, Hoffman HM, Person V, Lorenzen-Schmidt I, Bang ML, et al. The cardiac mechanical stretch sensor machinery involves a $\mathrm{Z}$ disc complex that is defective in a subset of human dilated cardiomyopathy. Cell 2002; 111: 943-955.

20. Sugaya T, Nishimatsu S, Tanimoto K, Takimoto E, Yamagishi T, Imamura $\mathrm{K}$, et al. Angiotensin II type 1a receptor-deficient mice with hypotension and hyperreninemia. J Biol Chem 1995; 270: 1871918722.

21. Akazawa H, Komazaki S, Shimomura H, Terasaki F, Zou Y, Takano $\mathrm{H}$, et al. Diphtheria toxin-induced autophagic cardiomyocyte death plays a pathogenic role in mouse model of heart failure. J Biol Chem 2004; 279: 41095-41103.

22. Rockman HA, Chien KR, Choi DJ, Iaccarino G, Hunter JJ, Ross J Jr, et al. Expression of a beta-adrenergic receptor kinase 1 inhibitor prevents the development of myocardial failure in gene-targeted mice. Proc Natl Acad Sci USA 1998; 95: 7000-7005.

23. Minamisawa S, Hoshijima M, Chu G, Ward CA, Frank K, Gu Y, et al. Chronic phospholamban-sarcoplasmic reticulum calcium ATPase interaction is the critical calcium cycling defect in dilated cardiomyopathy. Cell 1999; 99: 313-322.

24. Chien KR, Zhu H, Knowlton KU, Miller-Hance W, van-Bilsen M, O'Brien TX, et al. Transcriptional regulation during cardiac growth and development. Annu Rev Physiol 1993; 55: 77-95.

25. Mercadier JJ, Lompre AM, Duc P, Boheler KR, Fraysse JB, Wisnewsky C, et al. Altered sarcoplasmic reticulum Ca2(+)-ATPase gene expression in the human ventricle during end-stage heart failure. J Clin Invest 1990; 85: 305-309.

26. Mann DL. Mechanisms and models in heart failure: A combinatorial approach. Circulation 1999; 100: 999-1008.

27. Pfeffer MA, Pfeffer JM, Steinberg C, Finn P. Survival after an experimental myocardial infarction: Beneficial effects of long-term therapy with captopril. Circulation 1985; 72: 406-412.

28. Elsner D, Riegger GA. Characteristics and clinical relevance of animal models of heart failure. Curr Opin Cardiol 1995; 10: 253259.

29. Seidman JG, Seidman C. The genetic basis for cardiomyopathy: From mutation identification to mechanistic paradigms. Cell 2001; 104: $557-567$.

30. Zolk O, Caroni P, Bohm M. Decreased expression of the cardiac LIM domain protein MLP in chronic human heart failure. Circulation 2000; 101: 2674-2677.

31. Capasso JM, Li P, Zhang X, Meggs LG, Anversa P. Alterations in ANG II responsiveness in left and right myocardium after infarctioninduced heart failure in rats. Am J Physiol 1993; 264: H2056H2067.

32. Cheng CP, Suzuki M, Ohte N, Ohno M, Wang ZM, Little WC. Altered ventricular and myocyte response to angiotensin II in pacinginduced heart failure. Circ Res 1996; 78: 880-892.

33. Palomeque J, Sapia L, Hajjar RJ, Mattiazzi A, Vila Petroff M. Angiotensin II-induced negative inotropy in rat ventricular myocytes: Role of reactive oxygen species and p38 MAPK. Am J Physiol Heart Circ Physiol 2006; 290: H96-H106.

34. Tokuhisa T, Yano M, Obayashi M, Noma T, Mochizuki M, Oda T, et 
al. AT1 receptor antagonist restores cardiac ryanodine receptor function, rendering isoproterenol-induced failing heart less susceptible to $\mathrm{Ca}^{2+}$-leak induced by oxidative stress. Circ J 2006; 70: 777-786.

35. Omens JH, Usyk TP, Li Z, McCulloch AD. Muscle LIM protein deficiency leads to alterations in passive ventricular mechanics. Am J Physiol Heart Circ Physiol 2002; 282: H680-H687.

36. Lorenzen-Schmidt I, Stuyvers BD, ter Keurs HE, Date MO, Hoshijima M, Chien KR, et al. Young MLP deficient mice show diastolic dysfunction before the onset of dilated cardiomyopathy. J Mol Cell Cardiol 2005; 39: 241-250.

37. Costandi PN, Frank LR, McCulloch AD, Omens JH. Role of diastolic properties in the transition to failure in a mouse model of the cardiac dilatation. Am J Physiol Heart Circ Physiol 2006; 291: H2971-H2979.

38. Grossman W. Diastolic dysfunction in congestive heart failure. $N$ Engl J Med 1991; 325: 1557-1564.

39. Kass DA, Bronzwaer JG, Paulus WJ. What mechanisms underlie diastolic dysfunction in heart failure? Circ Res 2004; 94: 1533 1542 .

40. Yano M, Ikeda Y, Matsuzaki M. Altered intracellular $\mathrm{Ca}^{2+}$ handling in heart failure. J Clin Invest 2005; 115: 556-564.

41. Komuro I, Yazaki Y. Control of cardiac gene expression by mechani- cal stress. Annu Rev Physiol 1993; 55: 55-75.

42. Sadoshima J, Izumo S. The cellular and molecular response of cardiac myocytes to mechanical stress. Аппи Rev Physiol 1997; 59: $551-571$.

43. Bustamante JO, Ruknudin A, Sachs F. Stretch-activated channels in heart cells: Relevance to cardiac hypertrophy. J Cardiovasc Pharmacol 1991; 17(Suppl 2): S110-S113.

44. Brancaccio M, Fratta L, Notte A. Hirsch E, Poulet R, Guazzone S, et al. Melusin, a muscle-specific integrin beta1-interacting protein, is required to prevent cardiac failure in response to chronic pressure overload. Nat Med 2003; 9: 68-75.

45. Bendig G, Grimmler M, Huttner IG, Wessels G, Dahme T, Just S, et al. Integrin-linked kinase, a novel component of the cardiac mechanical stretch sensor, controls contractility in the zebrafish heart. Genes Dev 2006; 20: $2361-2372$

46. White DE, Coutu P, Shi YF, Tardif JC, Nattel S, St Arnaud R, et al. Targeted ablation of ILK from the murine heart results in dilated cardiomyopathy and spontaneous heart failure. Genes Dev 2006; 20: $2355-2360$.

47. Zou Y, Akazawa H, Qin Y, Sano M, Takano H, Minamino T, et al. Mechanical stress activates angiotensin II type 1 receptor without the involvement of angiotensin II. Nat Cell Biol 2004; 6: 499-506. 